\title{
Natural Hazards Modeling: From Runoff to Hyperconcentrated Flows - Roll Waves Generation
}

\author{
Fabiana de O. Ferreira, Geraldo de F. Maciel, Guilherme H. Fiorot, and Evandro F. da Cunha
}

\begin{abstract}
The aim of this article is to contribute to determination of generation criteria for roll waves in mud flows. Flow is represented byCauchy's equations system (general mass and momentum conservation equations), wherenon-Newtonian rheology (mud materials) is inserted and shallow water conditions are imposed, then leading to aroll waves model for laminar non-Newtonian viscous flow. Linear stability analysis is then applied and two criteria are established for roll waves generation: one related to Froude number and another by means of disturbance frequency. Confrontation of these criteria to numerical results is observed and good agreement is found regarding amplitude, length and propagation speed of roll waves. For Newtonian fluids, waves profile is also compared to experimental results. Preliminaries results based on non-Newtonian fluids experiments from literature are explored.
\end{abstract}

Index Terms-Mudflows, non-newtonian fluid, risks, roll waves.

\section{INTRODUCTION}

Natural hazards are, in fact, natural phenomena which may cause, directly or not, serious damage to buildings and people. In places where there is no human interest, those phenomena are not considered as disasters and are simply natural events. The magnitude of the damages suffered, results from a natural hazard, depends on the resilience of the targeted society which assumes the risks of that event. In other words, the so called hazards can just occur when a phenomenon, intrinsically dangerous, is convoluted with a systematical vulnerability of the target. Particularly in Brazil, we have encountered successive disastrous events such as floods, landslides and mudflows during the rainy season, from December to March, and, more recently, even small hurricanes. Regarding the landslides, the uncontrolled occupation of foothills and mountains unsafe areas associated with the rainfall intensification, leads to catastrophic scenarios, where the alliance between natural danger and vulnerability unfortunately succeeded. We can easily recall the last events occurred in the Brazilian territory, called as "predictable tragedies" by the local media. In this year, as results from extreme weather conditions and lack of effective social management, Rio de Janeiro State suffered from a

Manuscript received April 5, 2014; revised June 15, 2014.

F. O. Ferreira and E. F. Cunha are with Faculdade de Engenharia De Ilha Solteira, FEIS/UNESP, Brazil (e-mail: fabiana.of@gmail.com, evandrofernandesc@gmail.com).

G. F. Macielis is with the Civil Engineering Department from Faculdade de Engenharia de Ilha Solteira, FEIS/UNESP, Brazil (e-mail: maciel@dec.feis.unesp.br).

G. H. Fiorot is with the Laboratoire de Génie Civil et Génie Mécanique, Institut National des Sciences Appliquées de Rennes, LGCGM/INSA, France (e-mail: gfiorot@insa-rennes.fr). great catastrophe: 844 dead, 449 missing, 8,777 homeless and more than 20,000 people displaced (Data collected from the Civil Defense Department of Rio de Janeiro State on 28 January 2011). Rainfall reached high rates which, allied to the previous period of rain, promoted the instability of hills and the further mudflow configuration, causing destruction of houses, families, and leaving a tragic scenario behind. In 2010, the same state suffered from a landslide in Angra dos Reis. The occurrences list goes on, and is not restricted to one specific place. Santa Catarina, São Paulo, Pernambuco, Espírito Santo are all states where the same kind of phenomenon have been observed. It is true that disasters of this nature have been solved through palliative methods, which hardly recover the losses suffered by the affected ones. Corrective methods lessen the effects but do not prevent accidents, and considering the poor situation faced by many Brazilians, actions of prevention and managementshould be applied urgently to avoid further damage to this people and, for that, the mudflow phenomenon and others must be deeply studied and known.

The article presented here is within the context of mudflows characterized by the highly concentrated aqueous solution of sediment material that, in general, displays a non Newtonian behavior.Depending on flow conditions, waves can appear on the free surface of the flow; these instabilities are called roll waves. Their presence would significantly change the flow configuration, increasing the incurred risks

Despite many mathematical and numerical models had been developed to study this phenomenon [1]-[3], only few physical models were developed that could from experimental data greatly assist the exploration of data to the validation of mathematical models. In fact, there is a lack of experimental results of roll waves in the literature. In order to fill this gap, experiments carried by [4] made possible measure roll waves from data acquisition of free surface variation in time by light absorption method. Roll waves pattern presented in this article were acquired when a $3 \mathrm{~Hz}$ disturbance was applied to a Newtonian flow (glycerin). These experimental tests have proportioned good data exploitation and initial validation of both numerical and mathematical model developed by RMVP team (Rheology of Viscous and Viscoplastic Materials Research Group). Concerning Non-Newtonian fluids, in this this article just preliminaries numerical results are shown. The next stage of this research will focus on obtaining the same type of results for non-Newtonian fluids (carbopol solution), thus allowing new performance on models evaluation.

All characteristic parameters of tested fluids (glycerin and carbopol) were strictly controlled and measured. Rheometric parameters were obtained from the coaxial rheometer R/S that controls shear stress and shear rate. 


\section{MATHEMATICAL MODEL}

The modeling here presented was once developed by [3] taking as guide the classic work of [5], [1], [6], [7], which falls upon discontinuous functions for roll waves. This mathematical work was carried through Cauchy's equations inserting the Herschel Bulkley rheological model (3 parameters) at the viscous part of the stress tensor. Remark that the mathematical model presented in this section is dimensionless[8](Eq. (1) and (2)).

Continuity equation:

$$
\frac{\partial h}{\partial t}+\frac{\partial(h \bar{u})}{\partial x}=0
$$

Momentum equation:

$$
\begin{aligned}
& \quad \frac{\partial(\bar{u} h)}{\partial t}+\frac{\partial\left(\alpha \bar{u}^{2} h\right)}{\partial x}+\frac{1}{2 \mathrm{Fr}^{2}} \frac{\partial h^{2}}{\partial x} \\
& =h-C^{*} \\
& -(1 \\
& \left.-C^{*}\right)\left[\bar{u} h \frac{\left(1-C^{*}\right)\left(n+1+n C^{*}\right)}{\left(h-C^{*}\right)\left((n+1) h+n C^{*}\right)}\right]^{n}
\end{aligned}
$$

Froude number, Fr, and dimensionless parameter for yield stress, $C^{*}$, are calculated from steady flow condition: $C^{*}=$ $\tau_{c} /\left(\rho g h_{0} \sin \theta\right)$ and $\mathrm{Fr}=\bar{u} / \sqrt{g h_{0} \cos \theta}$, where $\mathrm{h}$ is the fluid height, $\bar{u}$, the mean flow velocity, $x$, longitudinal distance across the channel, $t$, the temporal variable, $n$ is the flow index, $\rho$ is the fluid density, $g$, gravity acceleration, $\theta$,channel steepness, $h_{0}$ is the fluid height in steady flow, and $\alpha$ is the momentum coefficient distribution, function of $h_{0}, \mathrm{n}$ and $C^{*}$. Through this system, it is possible to evaluate it as a representative dynamical system of the phenomenon and apply stability analysis.

\section{A. Linear Stability Analysis - Criteria for the Generation of Roll Waves}

Linear stability theory is a tool that allows us to obtain important information about the dynamical system, such as growth rate and propagation velocity of instabilities. Through this method, widely discussed by [9], [10], it is possible to characterize the necessary conditions to the formation of instabilities. [11] carried this theory to evaluate the convective nature of roll waves instabilities, i.e. demonstrate how waves can appear and grow in time and space if the conditions of the flow are favorable. The objective is to reach the dispersion equation for the system and analyze how infinitesimals disturbances of height and mean flow velocity ( $H(x, t)$ and $V(x, t)$, respectively) behave. Solving the system for $H(x, t)$, one single partial differential equation is found. From the linear theory, the surface wave problem is given by the solution of Laplace equation through the method of separation of variables. On the other hand, knowing the periodicity and uniformity of the solution, one can consider the perturbation of the form $H(x, t)=\widehat{H} e^{i(k x-\omega t)}$, where $\widehat{H}$ is the magnitude (constant), $k$, wave number and $\omega$, frequency of the perturbation.

\section{- $1^{\text {nd }}$ Criterion}

For disturbances to propagate downstream and amplify, the first instability generation criterion found through temporal stability analysis is shown on Eq. (3). The Froude number must be greater than a threshold value, $\mathrm{Fr}_{\text {min }}$, as determined by [3].

$$
F r>\operatorname{Fr}_{\min }=\frac{\vartheta}{\sqrt{\varphi^{2}-2 \alpha \varphi \vartheta+\alpha \vartheta^{2}}}
$$

where

$$
\begin{aligned}
& \left(n, C^{*}\right)=\frac{(n+1)(2 n+1)}{\left(n+1+n C^{*}\right)} \\
& \vartheta\left(n, C^{*}\right)=n\left(1-C^{*}\right)
\end{aligned}
$$

\section{- $2^{\text {nd }}$ Criterion}

The second criterion for the generation of instabilities is determined by analysis spatial stability, where: $\widehat{H}$, magnitude; $k$, wavenumber with $k=k_{r}+i k_{i}$; and $\omega$ disturbance frequency (real). The dispersion relation is then written as:

$$
k^{2}-\frac{(2 \alpha \omega+\varphi i) k+\left(\omega^{2}+\vartheta \omega i\right)}{\left(\alpha-\frac{1}{\mathrm{Fr}^{2}}\right)}=0
$$

Solving equation 6 :

$$
\begin{gathered}
k=\frac{1}{2} \frac{[(2 \alpha \omega-\varphi i) \pm \sqrt{a+b i}]}{\left(\alpha-\frac{1}{\mathrm{Fr}^{2}}\right)} \\
a=4 \omega^{2}\left(\alpha^{2}-\alpha+\frac{1}{\mathrm{Fr}^{2}}\right)-\varphi^{2} \\
b=4 \omega\left[\alpha \varphi-\alpha \vartheta+\frac{\vartheta}{\mathrm{Fr}^{2}}\right] \\
b=4 \omega\left[\alpha \varphi-\alpha \vartheta+\frac{\vartheta}{\mathrm{Fr}^{2}}\right]
\end{gathered}
$$

The frequency perturbation domain for roll waves generation is defined by $k_{r}>0$. Thus:

$$
\omega<\omega_{c}=a b s\left(\frac{1}{2 \alpha} \sqrt{\left(\alpha-\frac{1}{\mathrm{Fr}^{2}}\right) \vartheta^{2}-2 \alpha \vartheta \varphi}\right)
$$

\section{NUMERICAL SimULATIONS}

The generalized equations of mass and momentum conservation allow the inserting of the suitable rheological model in the stress tensor. The system of equations was discretized and properly approached by FLUENT software [12], using finite volume method and VoF scheme, as described by [8]. As roll waves appear in both Newtonian and non-Newtonian fluid flows, we initially made up the numerical representation of the system to Newtonian fluid flow's case using experimental results from the work carried out by [4], that used pure glycerin, highly viscous fluid (dynamic viscosity $\mu=0.206-0.217$ Pa.s).

The simulations were performed with a small sinusoidal perturbation of period $\mathrm{T}$ and magnitude (B) imposed on the uniform flow [8].

The first numerical test performed for non-Newtonian fluid was designed for power-law fluids [1], [9], which can be reached through the mathematical model adopted by ignoring the existence of a yield stress. The properties are given by: non-Newtonian fluid dynamic viscosity, $\mu_{n}=0.14 \mathrm{Pas}^{\mathrm{n}}$; density $\rho=1120 \mathrm{~kg} / \mathrm{m}^{3}$ and flow index, $n=0.4$. In this paper, tests were also made when considering the same fluid with a yield stress $\tau_{c}$. For both cases, analyzes were performed to verify generation and propagation of instabilities criteria. 


\section{ROLl WAVES GENERATION CRITERIA VERIFICATION FOR NEWTONIAN AND NON-NEWTONIAN FLUIDS}

The criteria are checked for fluid type Newtonian fluid and Herschel Bulkley, where the flow conditions are the same as shown in item A.

The first criterion is verified against the Froude number $\left(F r<\mathrm{Fr}_{\min }\right)$, as indicated in Eq. (3), wherein inserting the rheological properties of the fluid, there is the theoretical limit.

For Newtonian fluids, [13] found that for flows in the same configurations as here presented, Froude number must be greater than $1 / \sqrt{3}$ For this type of fluid, the index flow $n$ is equal to 1 , and no yield stress is taken into account $\left(\tau_{c}=\right.$ $\left.0 ; n=1, C^{*}=0\right)$, which gives $\vartheta=1$ and $\varphi=3$. Then, substituting in Eq. (3), we find the same result as [13]. The second criterion (here in dimensional variable) shows a favorable domain for frequency perturbation wave propagation $\left(f<f_{c}\right)$, dependent on the Froude number and the rheological properties of the fluid:

$$
f<f_{c}=\left(\frac{\omega}{2 \pi}\right) \frac{\bar{u}_{0}}{h_{0}}
$$

Table I shows the Froude number of the flow, the Froude number minimum necessary for the formation of waves and the critical frequency of disturbance, for Newtonian an non-Newtonian fluid (Herschel-Bulkley).

TABLE I: FLUID PROPERTIES, MiNIMUM CONDITIONS FOR ROLL WAVES Generation, Amplitude Wave $(\Delta \mathrm{H})$ AND WAVELENGTH $(\lambda)$

\begin{tabular}{|c|c|c|c|c|c|c|}
\hline Properties & \multicolumn{3}{|c|}{ Newtonian fluid } & \multicolumn{3}{|c|}{ Herschel-Bulkley } \\
\hline$\tau_{\mathrm{c}}(\mathrm{Pa})$ & \multicolumn{3}{|c|}{0} & \multicolumn{3}{|c|}{0.2} \\
\hline $\mathrm{C}^{*}$ & \multicolumn{3}{|c|}{0} & \multicolumn{3}{|c|}{0.1774} \\
\hline $\mathrm{Fr}$ & \multicolumn{3}{|c|}{0.83} & \multicolumn{3}{|c|}{0.5313} \\
\hline $\mathrm{Fr}_{\min }$ & \multicolumn{3}{|c|}{$1 / \sqrt{3}$} & \multicolumn{3}{|c|}{0.2176} \\
\hline $\mathrm{f}_{\mathrm{c}}(\mathrm{Hz})$ & \multicolumn{3}{|c|}{4.82} & \multicolumn{3}{|c|}{1.92} \\
\hline \multirow{2}{*}{$\begin{array}{l}\text { Amplitude } \\
\text { wave and } \\
\text { wavelength }\end{array}$} & \multicolumn{3}{|c|}{ Frequencies $(\mathrm{Hz})$} & \multicolumn{3}{|c|}{ Frequencies $(\mathrm{Hz})$} \\
\hline & 1.0 & 3.0 & 4.0 & 0.5 & 0.8 & 1.0 \\
\hline$\Delta \mathrm{h}(\mathrm{m})$ & 0.0064 & 0.003 & 0.0011 & 0.0025 & 0.0016 & 0.00086 \\
\hline$\lambda(\mathrm{m})$ & 0.7500 & 0.210 & 0.1500 & 0.7400 & 0.5300 & 0.35000 \\
\hline
\end{tabular}
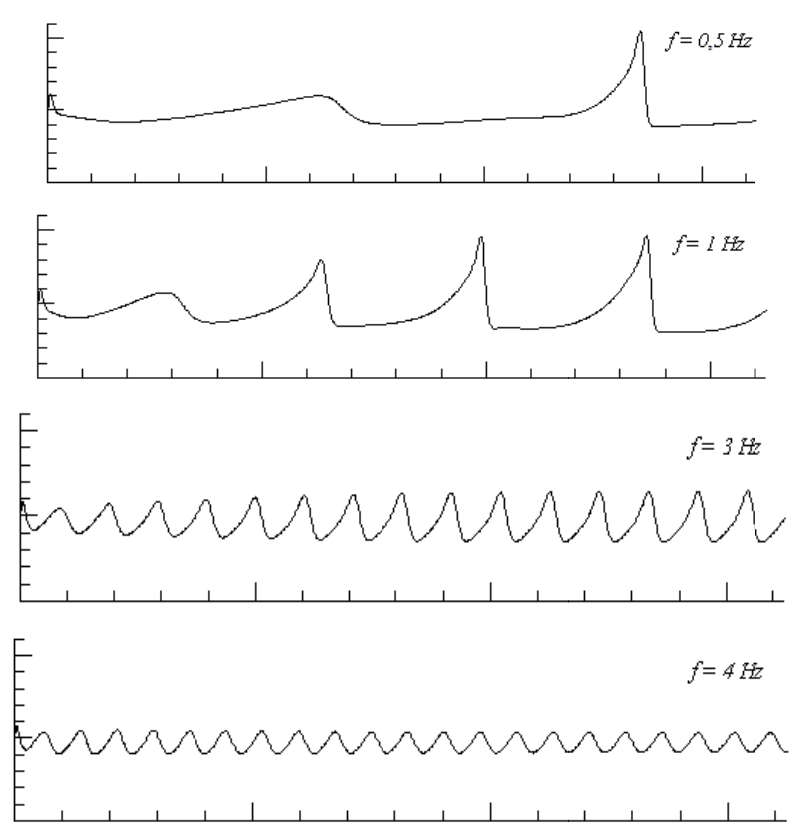

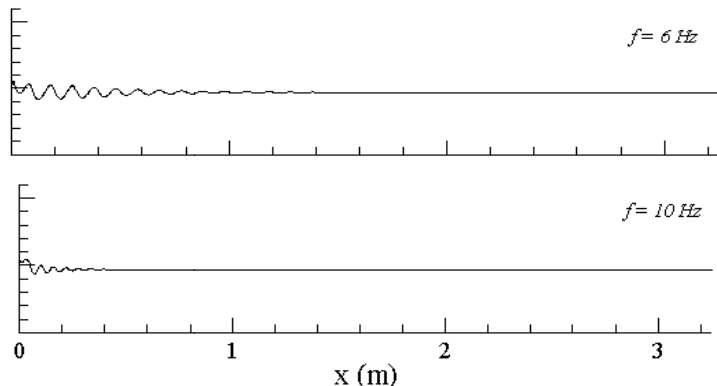

Fig. 1. Simulations for Newtonian fluid, and disturbance frequencies: 0.5, 1 , 3,4 and $\mathrm{Hz}$.

Through the data presented in Table I it can be seen that in both cases the Froude number of the flow is higher than the critical condition for generation of wave roll. It is also observed that the limit of the critical disturbance frequency decreases with the increase of yield stress of the fluid. In order to verify the validity of the critical disturbance frequency, simulations were performed for the Newtonian fluid for disturbance frequencies $0.5,1,3,4,6$ and $10 \mathrm{~Hz}$, as shown in Fig. 1.

It can be seen that for a disturbance frequency of $4.82 \mathrm{~Hz}$, waves dampened, i.e. above the critical frequency (Table I) there is no occurrence of roll waves. The same findings were made for the Herschel-Bulkley fluid with yield stress of $0.2 \mathrm{~Pa}$, for disturbance frequencies of $0.5,0.8,1$ and $2.5 \mathrm{~Hz}$, as shown in Fig. 2.
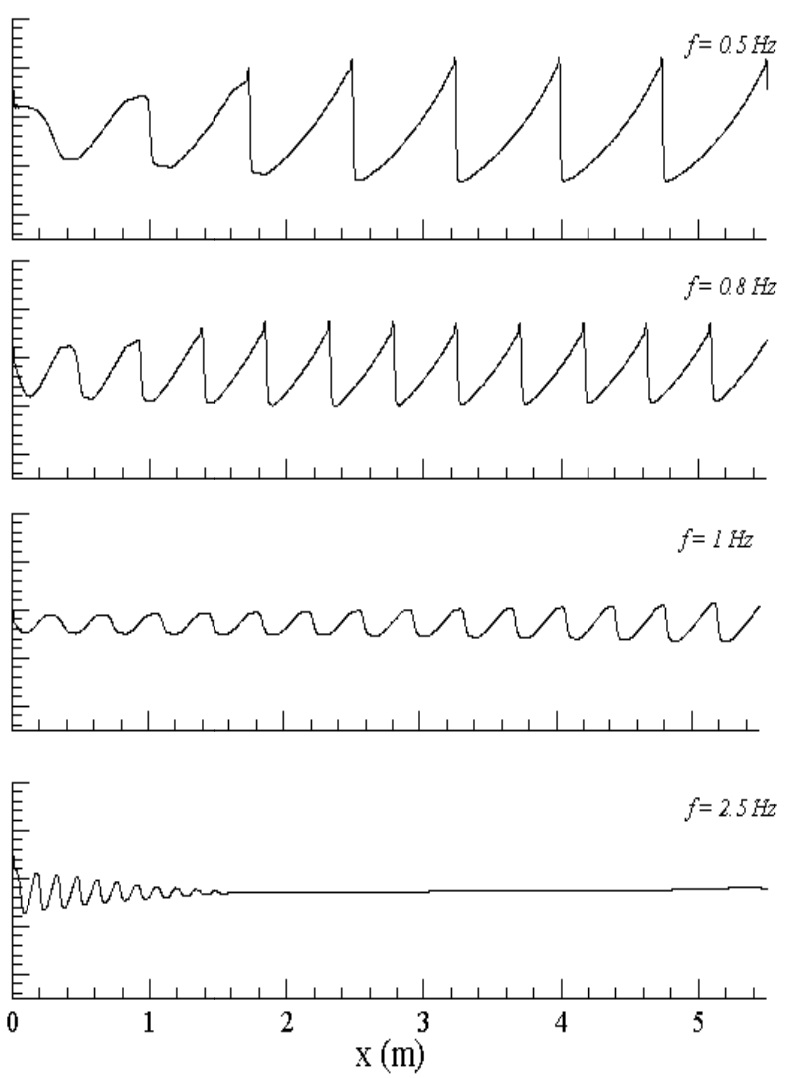

Fig. 2. Simulations for non-Newtonian fluid and disturbance frequencies: $0.5,0.8,1.0$ and $2.5 \mathrm{~Hz}$.

Regarding the first criterion, it should be noted that although the simulations were performed in the roll waves favorable domain of generation, not every frequency of disturbance resulted in the propagation of these waves, which proves that the condition $F r>F r_{\text {min }}$, is necessary but not 
sufficient.

Note that for non-Newtonian fluid, the critical frequencies are low, which may result in realistic conditions waves of larger amplitudes and lower wavelength.

\section{COMParison Between Numerical Simulations USING THE FLUENT AND EXPERIMENTAL RESULTS}

This item shows the comparison between numerical and experimental results of [4]. The used fluid is glycerin with Newtonian properties, though highly viscous, whose viscosity is measured after each test. Measurements were made by fixing a flow rate $(Q)$ for the inclined channel at 8 degrees, considering a favorable field for the generation of instabilities at the free surface, i.e., to: $F r>1 / \sqrt{3}$.

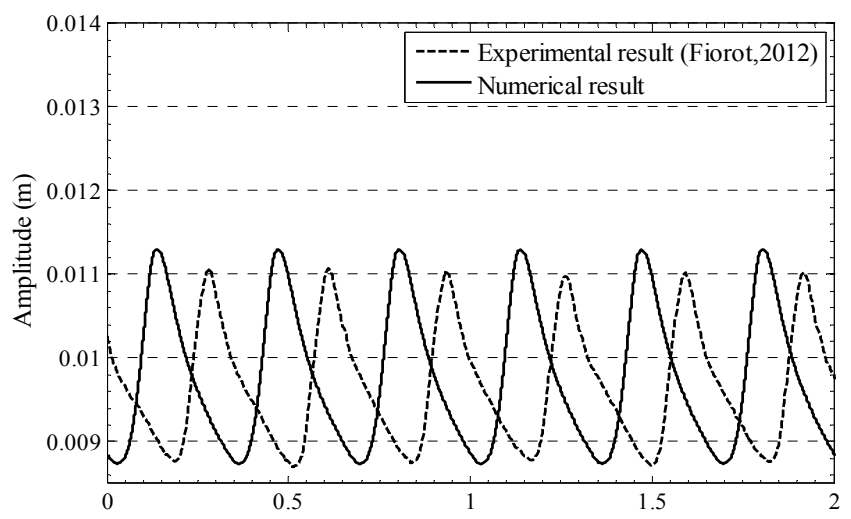

(a)

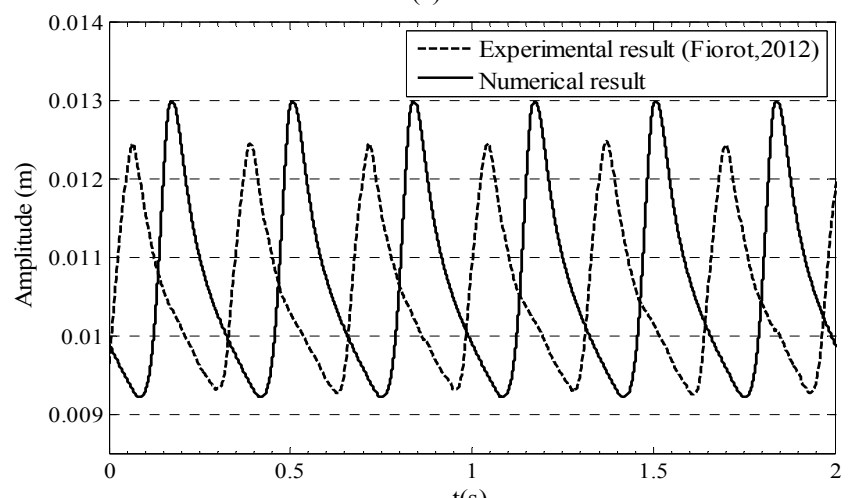

(b)

Fig. 3. Comparison between experimental (Fiorot, 2012) and numerical results for: (a) $Q=0.75 \mathrm{l} / \mathrm{s}$; (b) $Q=0.96 \mathrm{l} / \mathrm{s}$.

TABLE II: COMPARISON OF THE EXPERIMENTAL RESULTS [4] AND NUMERICAL REFERRING TO FIGURE 3

\begin{tabular}{ccccccc}
\hline \multicolumn{3}{c}{ Discharge:0,75 $l / s$} & \multicolumn{3}{c}{ Discharge:0,96 l/s } \\
\hline \multirow{2}{*}{ Parameters } & $\begin{array}{c}\text { Exp. } \\
\text { results }\end{array}$ & $\begin{array}{c}\text { Num. } \\
\text { results }\end{array}$ & $\begin{array}{c}\text { Error } \\
(\%)\end{array}$ & $\begin{array}{c}\text { Exp. } \\
\text { results }\end{array}$ & $\begin{array}{c}\text { Num. } \\
\text { results }\end{array}$ & $\begin{array}{c}\text { Error } \\
(\%)\end{array}$ \\
\hline $\bar{u}_{0}(\mathrm{~m} / \mathrm{s})$ & 0,258 & 0,256 & 0,35 & 0,297 & 0,298 & 0,40 \\
Fr & 0,83 & 0,83 & 0,07 & 0,92 & 0,925 & 0,50 \\
$\Delta h(\mathrm{~mm})$ & 2.25 & 2.65 & 17,70 & 3.156 & 3.97 & 25,80 \\
$T(\mathrm{~s})$ & 0.33 & 0.33 & - & 0.33 & 0.33 & - \\
\hline \hline
\end{tabular}

Fig. 3 shows a good similarity between the form and frequency of the waves generated by the model. Furthermore, concerning the amplitude ratio and flow wave, it is possible to observe that the increase in flow rate produces a raise in the amplitude of the waves generated.

Fig. 3 shows that for a low flow, the discrepancy in the amplitude of roll waves is small. However, when the flow rate increases, the error increasessignificantly.

From Table II, it is possible to observe that there is an error between the experimental and numerical average flow velocity. This is because the imposed average speeds in the numerical model; it is calculated considering as input parameters the experimental flow conditions: channel slope, normal depth and fluid properties (density and dynamic viscosity) [9]. Any error in the measurements of these parameters influences the numerical average velocity and; hence, the Froude number, which is an important parameter in defining the roll waves.

\section{DISCUSSION}

The numerical and experimental results of roll waves generation were presented, whereas such waves stem from a disturbance imposed on uniform flow. In this, the propagation or not propagation of these waves depends on two criteria: the first associated with inertial and gravitational forces of the flow (Froude number), and the second with the frequency of disturbance. To simulate the Newtonian fluid, the experimental data obtained by [4] are inserted in the numerical model. To simulate the non-Newtonian, data with a power law fluid tested by [1] with the yield stress are inserted in model to check the validity of the criteria for generation of roll waves in Herschel Bulkley fluid flows. Through these simulations were possible to validate the criteria for generation to both cases.

In respect to the physical model developed within the RMVP team [4], this has enabled measurements of roll waves in Newtonian fluid, there are few works in literature that show similar results [1], [3], [8], [11]. A comparative study between the numerical and physical models has been developed, achieving good concordance in respect toshape, amplitude and wave period.

Finally, from these models we check the reproducibility of the phenomenon and improve the estimate of additional risks when roll waves are present in mudflows events.

\section{ACKNOWLEDGMENT}

We'd like to thank FAPESP, CNPq and CAPES project for scholarship and also project support.

\section{REFERENCES}

[1] C. O Ng and C. C. Mei, "Roll waves on a layer of fluid mud modelled as a power law fluid," Journal of Fluid Mechanics, vol. 263, pp. 151-184, 1994.

[2] N. J. Balmforth and C. Mandre, "Dynamics of roll waves," Journal of Fluid Mechanics, Cambridge, vol. 514, pp. 1-33, 2004.

[3] G. F. Maciel, F. O. Ferreira, and G. H. Fiorot, "Control of instabilities in non-newtonian free surface fluid flows,"J. of the Braz. Soc. of Mech. Sci. \& Eng., Rio de Janeiro, vol. 35, no. 3, pp. 217-229, 2013.

[4] G. H. Fiorot, "Mitigação de riscos e catástrofes naturais: análise numérico-experimental de Roll waves evoluindo em canais inclinados," M.Sc. thesis, Faculdade de Engenharia, Universidade Estadual Paulista,UNESP, Ilha Solteira-SP, Brazil, 2012.

[5] R. F. Dressler, "Mathematical solution of the problem of roll waves in inclined open channels," Communications on Pure and Applied Mathematics, New York, vol. 2, pp. 149-194, 1949.

[6] J. P. Pascal, "Instability of power-law fluid flow down a porous incline," Journal of Non Newtonian Fluid Mechanics, vol. 133, no. 2-3, pp. 109-120, 2006.

[7] C. D. Cristo, M. Iervolinoand, and A. Vacca, "On the applicability of minimum channel length criterion for roll-waves in mud-flows," $J$. Hydrol. Hydromech, vol. 61, no. 4, pp. 286-292, 2013. 
[8] F. O. Ferreira, "Estabilidade e controle dinâmico de roll waves," Ph.D. dissertation, Faculdade de Engenharia, Universidade Estadual Paulista,UNESP, Ilha Solteira-SP, Brazil, 2013.

[9] P. Huerre and P. A. Monkewitz, "Local and global instabilities in spatially developing flows," Annual Review of Fluid Mechanics, vol. 22, Annual Reviews, California, pp. 473-537, 1990.

[10] R. J. Briggs, Electron-Stream Interaction with Plasmas, MIT Press, 1964, p. 183

[11] D. Cristo and C. Vacca, "On the convective nature of roll waves instability," Journal Applied Mathematics, vol. 3, pp. 259-271, 2005.

[12] FLUENT 6.3. User's Guide, Lebanon: Fluent Incorporated, 2006. $2501 \mathrm{p}$.

[13] T. Ishihara, Y. Iwagaki, and Y. Iwasa, "Theory of the roll wave train in laminar water flow on a steep slope surface," Transactions JSCE, Japan, 1954, vol. 19, pp. 46-57.

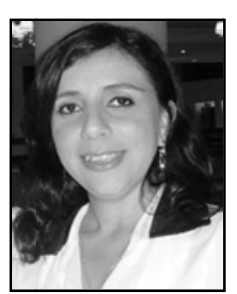

Fabianade O. Ferreira has B.S. degree in mathematics (2000) by Faculdade de Ciências e Tecnologia, FCT/UNESP, Presidente Prudente, Brazil, She received her M.Sc. degree in mechanical engineering 2007 and She received her Ph.D. degree in electrical engineering both from Faculdade de Engenharia de IlhaSolteira, FEIS/UNESP, Brazil.

She is currently a postdoctoral researcher at FEIS/UNESP, Ilha Solteira and cooperates with RMVP Team (Grupo de EstudosemReologia de Materiais Viscosos e Viscoplástico - $\mathrm{CNPq}$ certified) developing a mathematic and numerical modeling for non-Newtonian fluid flow and visualization of roll waves. Her main interests are numerical analysis of dynamical system.

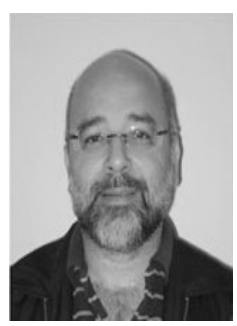

Geraldo de F. Maciel received the B.S. degree in civil engineering by Universidade Federal do Rio de Janeiro, Brazil, and the M.Sc. in oceanic engineering and Ph.D. in mechanical from Université de Grenoble I (Scientifique et Médicale - Joseph Fourier) degrees France. He did postdoctoral research (1996-1998) at INSA (Institut National des Sciences Appliquées) of Toulouse and most recently at INSA Rennes (2011-2012).

$\mathrm{He}$ is currently a full professor at the Civil Engineering Department from Faculdade de Engenharia de Ilha Solteira,FEIS/UNESP, Ilha Solteira, SP, Brazil, Researcher CNPq and coordinator of RMVP Team (Grupo de Estudos em
Reologia de Materiais Viscosos e Viscoplástico - CNPq certified).Was associate professor (Past Etranger) at INSA Toulouse in $2000-2003$ and since 2004 is Visiting Professor at the same institute.His main interests are in experimental and numerical analysis of free surface flows with Newtonian and non-Newtonian fluids in order to applicate at natural hazards.

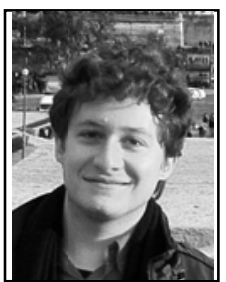

Guilherme H. Fiorot had his bachelor degree in electrical engineering in 2009 from Faculdade de Engenharia de IlhaSolteira, FEIS/UNESP, Brazil, he received his master of science degree in mechanical engineering (Fluid Mechanics) from the same Institution in 2012. He started his Ph.D. degree in that year at Laboratoire de Génie Civil et Génie Mécanique on Institut National des Sciences Appliquées de Rennes, France.

He started his research career in 2008 developing numerical analysis of dynamical system. During his M.Sc. degree he cooperated with RMVP Team (Grupo de Estudosem Reologia de Materiais Viscosos e Viscoplástico - $\mathrm{CNPq}$ certified) developing an experimental test-bench for roll waves simulation and measurement. His Ph.D project, funded by Conselho Nacional de Desenolvimento Científico e Tecnológico $\mathrm{CNPq}$ (scholarship), tries to study in more general way how roll waves contribute to mudflows/mud floods formation, from diluted water turbulent flow to hyper concentrated laminar flow occurring over porous bed.

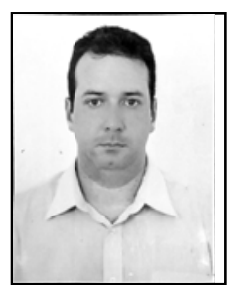

Evandro Fernandes da Cunha graduated in telecommunication engineering at University Center Salesian Catholic Auxiliun in 2006, with specialization in safety engineering work by Paulista Foundation of Technology and Education in 2011 and the masters in mechanical engineering from Universidade Estadual PaulistaJúlio de Mesquita Filho in 2013. Currently he is a professor at Paula Souza Center I - State Technical School Single Island and a Ph.D. in mechanical engineering from Universidade Estadual Paulista Júlio de Mesquita Filho. He has experience in electrical engineering with emphasis in electrical, electronic and photonic measurements; instrumentation. 